\title{
Characteristics of Droplet Formation Between Diesel Fuel, Emulsion and Pure Water
}

\author{
Nyenyep Sriwardani, Basori \\ Mechanical Engineering Education \\ Teacher Training and Education Sebelas Maret University \\ Surakarta, Indonesia \\ daniptm@fkip.uns.ac.id, basori@fkip.uns.ac.id
}

\begin{abstract}
Spray is widely used in the development of nanotechnology, both in the automotive and the industrial sector. The perfect mist is one of which is determined by droplet formation. Therefore, it is necessary to research the droplet formation characteristics of the fluid. Research begins by observing the trend of spray trajectories of diesel fuel with pressure variation. The effects of increased pressure produce a thick trajectory, filled with shadows. This shows that the liquid sprayed has largely been turned into a droplet. The next is observation of droplet formation characteristics. The study was conducted by observing the dripping process of a droplet from a disposable syringe with needle. Variety of fluids used diesel fuel, emulsion and pure water. Observation of the experiment The distance of the syringe, the diameter droplet that is formed and stretch from each droplet before dropping. The data analysis shows that diesel fuel has the greatest distance, the largest diameter and the longest stretch. While emulsion fuel has droplet formation with the smallest diameter droplet size and more solid so the stretch is the least, and the displacement is shorter than diesel fuel. While pure water has the shortest travel distance. This indicates that flocculation occurs due to the water phase being dispersed into the oil phase. Therefore, the composition should be considered to reduce the formation of inner phases that increase the viscosity of the emulsion.
\end{abstract}

Keywords—spray; drople; diesel fuel; emulsion; pure water.

\section{INTRODUCTION}

Some interacting of fluid mechanics can give an effect to the chemical processes. Recently, liquid spray offers a major contribution to meet the world's demand on the energy. The application of spray combustion in high energy density is prevaporizing systems like afterburner and ramjets, liquid rocket motor, gas turbine, industrial furnace and diesel engines [1]. Spray combustion has been used very widely as engine energy [2]. Especially in the worldwide development of transportation, providing high performance of aircrafts and diesel engines [1]. Oil-fired furnaces also employ spray combustion [3]. While the energy is a key condition for the survival of the human race, there is an ethics that should not be ruled out in the effort to meet the energy needs. Even more with the rise of global warming issues, exhaust gas emission is the most highlight aware by scientist. The emulsion fuel utilization in spray combustion has benefits of potential control of the simultaneous lower NOx emission [4] even thought enhancement of combustion due to secondary atomization [5].
However, combustion is a dynamic process that caused by interacting between chemical process and physical processes. The interaction between both fluids destabilizes the liquid flow, causing its rupture in droplets [6]. Droplet formation can be reduced by decreasing liquid flow rate. The gas-assisted atomization is also hindered by viscosity [7] in [6]. The combustion reaction doesn't occur directly, rather dissociated at the first time to be radical molecule that initiates as a chain step. Consider to the reference [8], the simplest example is the chain branching steps at the $\mathrm{H}_{2}-\mathrm{O}_{2}$. The assumption which consider to the chain steps said that the most important of various chain types is the chain step that is necessary to achieve nonthermal explosions. The actual condition called as chain branching. The reaction system could be illustrated with:

$$
\begin{aligned}
& \mathrm{H} \cdot+\mathrm{O}_{2} \rightarrow=\mathrm{OH}+\cdot \mathrm{O} . \\
& =\mathrm{O} \cdot+\mathrm{H}_{2} \rightarrow \mathrm{OH}+\mathrm{H} .
\end{aligned}
$$

The dots represented the convention for designating radicals. There are inspired the research on characteristics of droplet formation between diesel fuel, emulsion and pure water.

\section{EXPERIMENTAL APPARATUS AND PROCEDURE}

The present research investigated droplet formation. The experiments were conducted in two stages. The first phase of the study was carried out by observing the spray path on diesel fuel with spray pressure variations of $50 \mathrm{psi}, 150 \mathrm{psi}$ and 200 psi. The pictures taken with the camera. Further data obtained are presented in the form of drawings and trend diagram of spray. The second stage of research is done by observing the process of droplet formation. The apparatus used is a disposable syringe with needle with specification $10 \mathrm{ml}$ $21 \mathrm{Gx} 1 \frac{1}{2} 2$ ". The observed fluids are diesel fuel, emulsion and pure water. The emulsion is a mixture of diesel fuel with pure water plus $\mathrm{W} / \mathrm{O}$ emulsifier. Picture taken with the camera. Data collection is conducted three times on each fluid. The first data is obtained when the liquid fluid begins to form a droplet, secondly, when a droplet is complete formation, and the third is after the droplet has maximum stretch. Further data is processed and displayed in the form of drawings and diagrams. Data analysis was done descriptively qualitative. The apparatus for investigating spray characteristics used series of reservoir/fuel tank, diaphragm pump, pressure gauge, pressure regulator, injector, battery, and switch. 


\section{A. Experimental Apparatus}

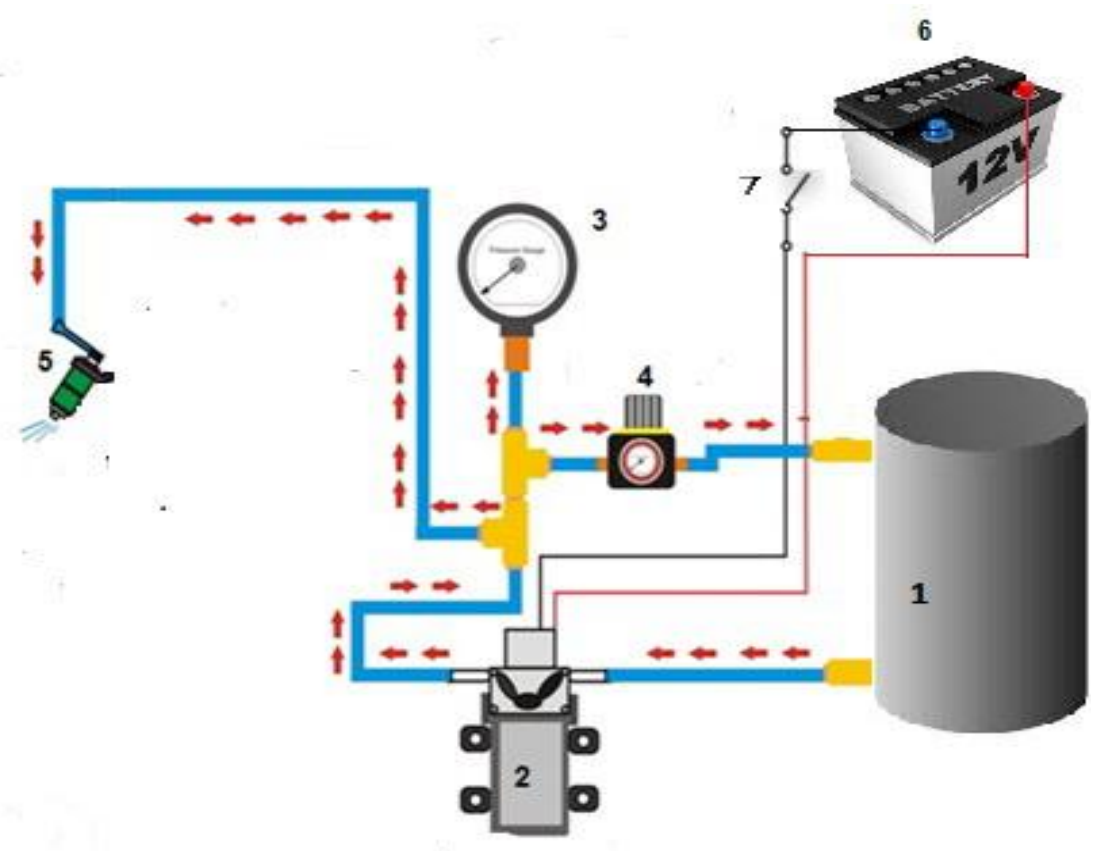

Fig. 1. Experimental Apparatus for Investigate Spray Characteristics

\section{Description:}

(1) Reservoir/fuel tank

(2) Diaphragm pump

(3) Pressure gauge

(4) Pressure regulator

(5) Injector

(6) Battery

(7) Switch

\section{B. Experimental Procedure}

When Switch (7) is on, the current from the battery (6) will flow to the Diaphragm pump (2), there is a fluid pumping from the tank (1) to be forwarded to the injector (5). The flowing of pressure is regulated by the pressure regulator (4) manually. The amount of pressure can be seen in the pressure gauge (3). If the pressure is excess of adjusted pressure, then the excess flow will return to the tank (1), while the pressure that has been set will flow to the injector. From the injector, the pressurized flow that has been set will be sprayed / injected out to find out the pattern of spray path form.

\section{SPRAY TRAJECTORY}

There are several parameters in the atomization process such as the physical properties and the flow characteristics of both injected liquid and surrounding air. The geometry of the atomizer contributes to the formation of the final spray [9]. Spray pressure will have a great effect on the characteristics of droplet formation.

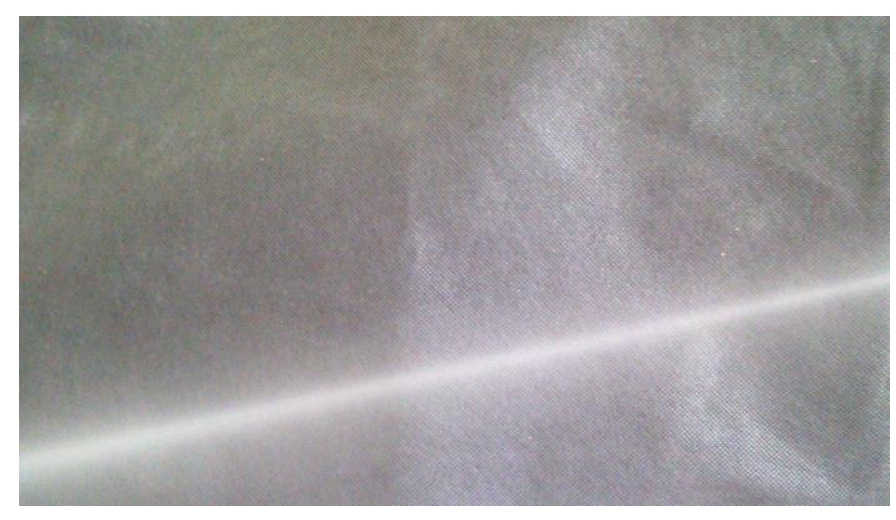

Fig. 2. Spray of Diesel Fuel at 50 psi

Figure 2 is a path form of diesel fuel sprayed with a pressure of $50 \mathrm{psi}$. The apparent line indicates that the droplets are formed relatively little number, so the fuel that spurt is still in liquid form. 


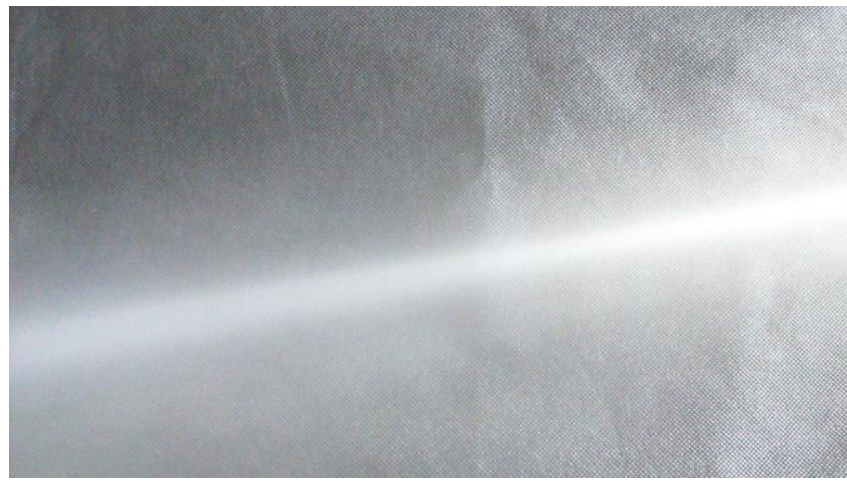

Fig. 3. Spray of Diesel Fuel at $150 \mathrm{psi}$

Figure 3 is a path form of diesel fuel sprayed with a pressure strength of 150 psi. The shadows around the path are the droplets formed. The trajectory line filled with shadows indicates that many droplets are already formed, so the liquid fuel turns into an almost perfect mist.

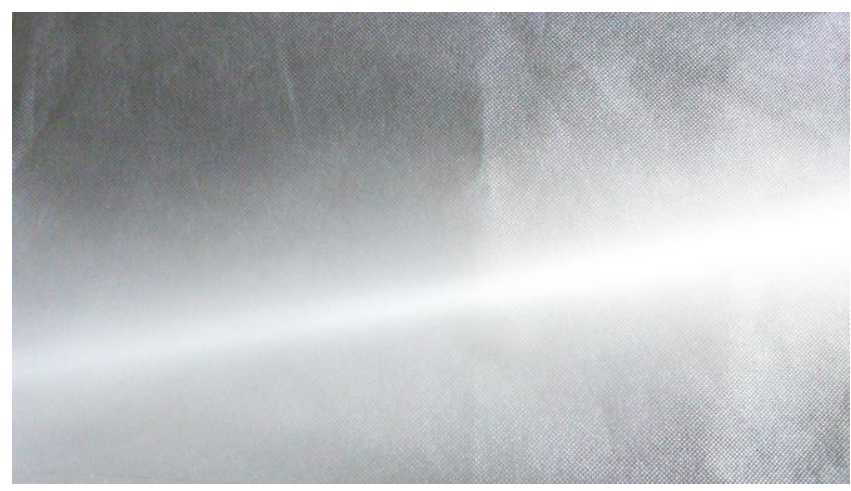

Fig. 4. Spray of Diesel Fuel at 200 psi

Figure 4 is a path form of diesel fuel sprayed at the pressure of 200 psi. Line trajectory still appears at the beginning, then faded as a whole. This indicates that the fuel in droplet forms completely.

\section{DROPLET FORMATION}

A fluid droplet that out from a disposable syringe with needle is observed to determine the droplet formed characteristics by slow spraying the fluid. The independent variables are three different types of liquids, the diesel fuel representing fuel from diesel fuel as fluid hydrocarbon, emulsion and pure water. From the observation of fluid movement to a drip, obtained the data as follows:
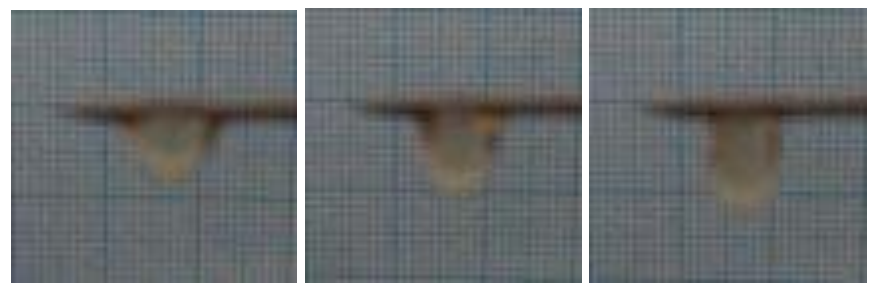

Fig. 5. Droplet Formation of Diesel Fuel
Figure 5 is the stage of droplet formation of liquid diesel fuel that will be dripping from a disposable syringe with needle. The liquid fuel move from the tip syringe to the middle along the $7 \mathrm{~mm}$ then widened to form a semi-circle with a diameter of $12 \mathrm{~mm}$. Before drip to the ground, the droplet stretch reaches $14 \mathrm{~mm}$.
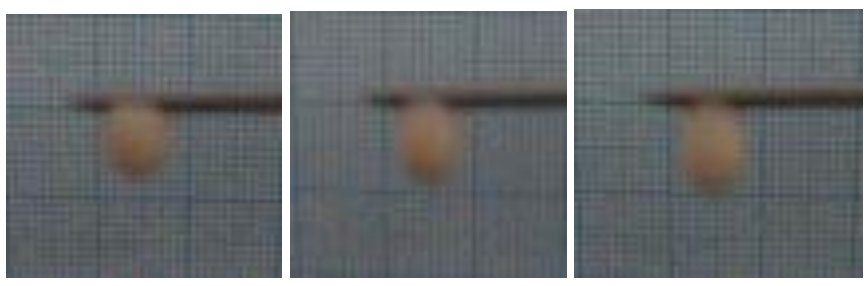

Fig. 6. Droplet Formation of Emulsion fuel

Figure 6 is the stage of droplet formation of liquid emulsion that will be dripping from a disposable syringe with needle. The emulsionl move from the syringe tip to the middle along the $4 \mathrm{~mm}$ then extends to form an elliptical cut with a width of $7 \mathrm{~mm}$ and a height of $8 \mathrm{~mm}$. Before drip to the ground, the droplet stretch reaches $10 \mathrm{~mm}$.
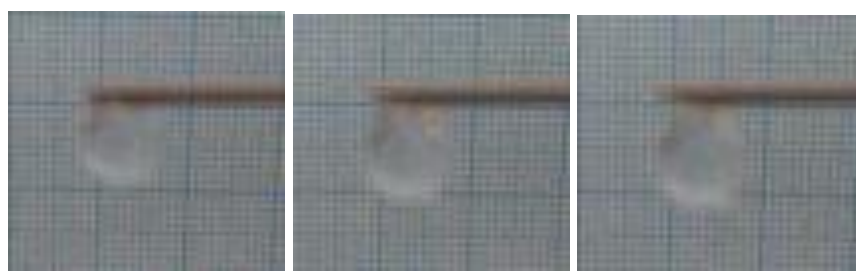

Fig. 7. Droplet Formation of Pure Water

Figure 7 is the stage of droplet formation of pure water that will be dripping from a disposable syringe with needle. The liquid move from the syringe tip to the middle along the $1 \mathrm{~mm}$ then widened to form a sphere with a diameter of $10 \mathrm{~mm}$. Before drip to the ground, the droplet stretch reaches $13 \mathrm{~mm}$.

\section{RESULT}

The data have been obtained can be presented in the form of diagrams as follows:

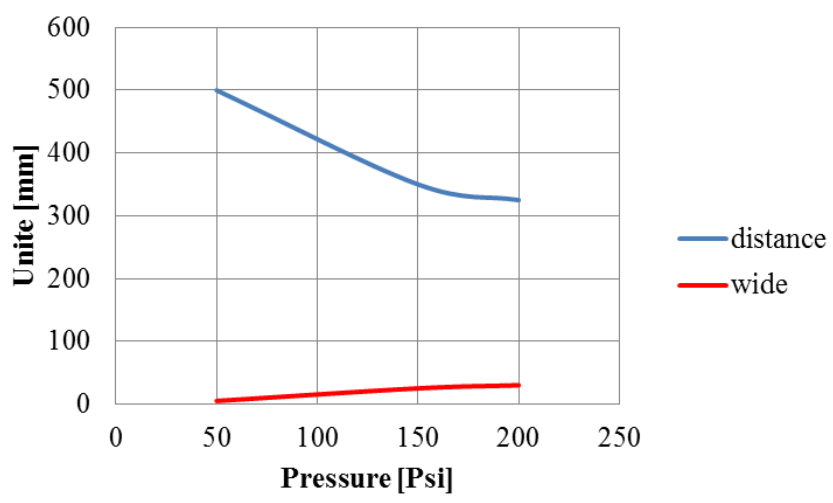

Fig. 8. Trend of Liquid Spray Path 
Figure 8 is Trend of the liquid spray model. At the time of low spraying pressure the liquid sprayed with a long spray distance, and form a narrow line because only a little droplet formed. As the pressure on spraying increases, the change in length of the fluid becomes shorter, and the length of spray decreases too. The pressure also affects the number of droplet formation. The higher of pressure produced more perfect droplet formation, that's proven from the shadows of the path are wider.

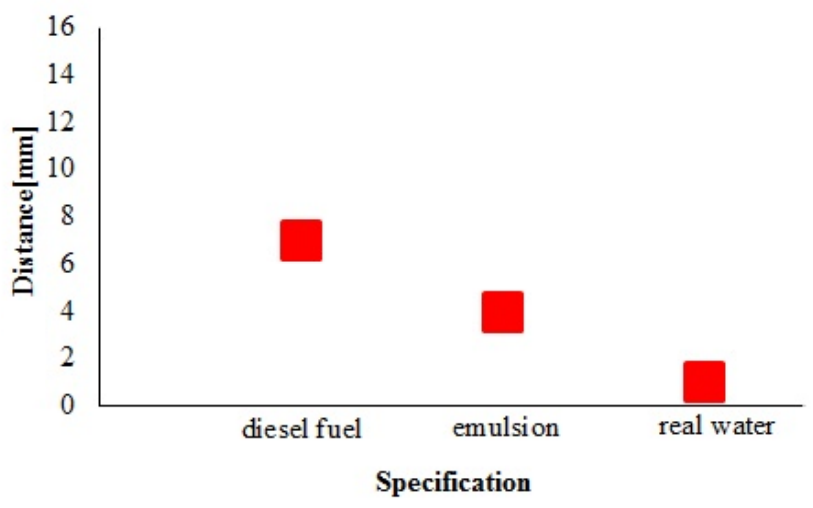

Fig. 9. The Distance of Droplet Formation From the Tip of a Disposable Syringe with Needle

Figure 9 is distance of transfer fluid coming out from the end of a disposable syringe with needle tip at the time of the change process fluid flows into a droplet dripping.

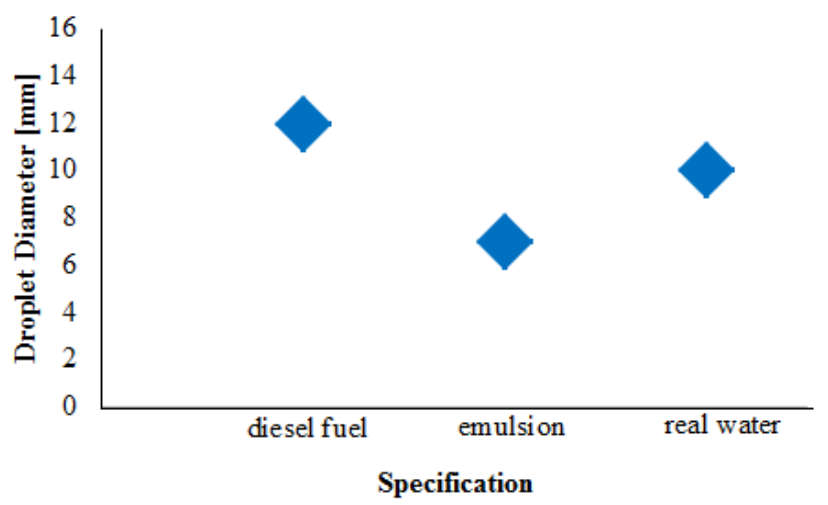

Fig. 10. Droplet Diameter of Diesel Fuel, Emulsion and Pure Water

Figure 10 is droplet diameter of diesel fuel, emulsion and pure water discharge out of disposable syringe with needle tip and has moved to the center of the syringe with distance as shown in figure 9.

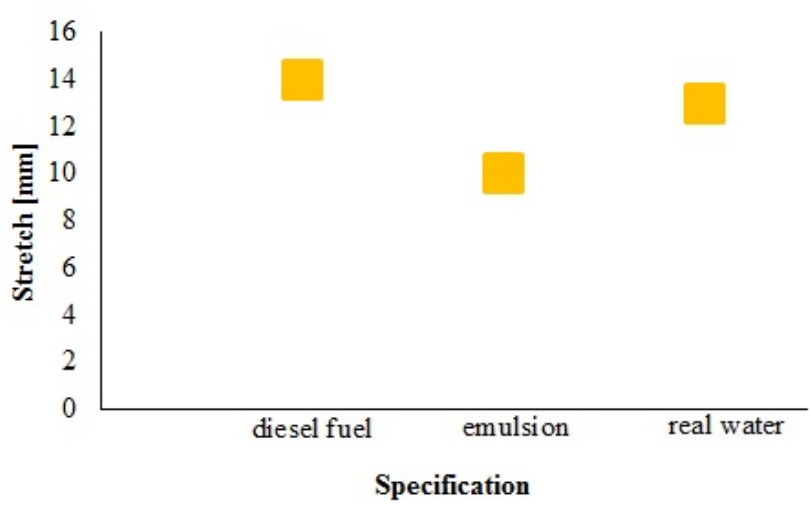

Fig. 11. Stretching Droplet Before Dripping

Figure 11 is the stretch that occurs due to the pull of gravity, so drip from a disposable syringe with needle to the earth.

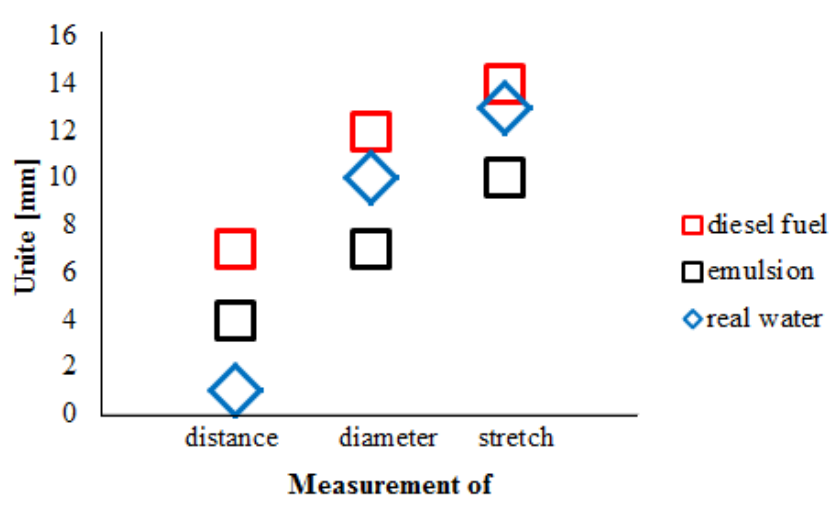

Fig. 12. The Distance, Diameter and Stretch with Fluid Variation

Figure 12 is comparison of fluid displacement distance, droplet diameter produced and maximum stretch of diesel fuel, emulsion and pure water. Dieles fuel can move the farthest, then emulsion and the last is pure water. The most large of droplet diameter is diesel fuel, then pure water, and finally is emulsion fluid. While the maximum stretch of the droplet is diesel fuel and the pure water slightly below it. The emulsion is the shortest stretch.

\section{CONCLUSION}

The present research investigated droplet formation between diesel fuel as hydrocarbon fuel, liquid emulsion and pure water. The emulsion is a mixture of diesel fuel with water and emulsifier. The expected properties of mixing are to obtain liquid fuel with optimum characteristics. Physically characteristic of the emulsion is experiencing of movement with distance on the place between diesel fuel and pure water. The possibility of liquid emulsion is having medium viscosity. This fluid can produce the smallest droplets and stretch the shortest of diesel fuel and also compare with pure water, so if it can be atomized certainly not so perfect. Droplet diesel fuel has the largest droplet diameter, longest displacement distance and 
longest stretch before drip. And the droplet from pure water has a larger diameter from emulsion, the shortest displacement distance and stretch longer than the emulsion. From the data processing, it can be concluded that the mixing of diesel fuel and pure water with w/o emulsifier will be obtained emulsion with droplet diameter size is the smallest but looks more solid because it is more difficult to stretch. The emulsion of the interaction of aqueous phase dispersed in the oil phase, exhibits a tendency for flocculation or clumping which is physically visible by the increase of viscosity. This condition certainly does not support the mist process when applied as a spray fluid. It is therefore necessary to pay attention to the inner phase volume of the emulsifying process, so that emulsion fuel can enable it to be environmentally friendly fuel in spray combustion.

\section{ACKNOWLEDGMENT}

To the Laboratory of Mechanical Engineering Education of Teacher Training and Education Sebelas Maret University Surakarta that granting permit used research facilities. And also we give acknowledgment to the Faculty of Engineering Yogyakarta State University, which held the International Conference of Technology and Vocational Teachers (ICTVT 2017).

\section{REFERENCES}

[1] Faeth, "Current status of droplet and liquid combustion," Energy and Combustion Science, pp. 149-182, 1979.

[2] Candel, S., Durox, D., Schuller, T., Darabiha, N., Hakim, L., Schmitt, T., "Advances in combustion and propulsion applications," European Journal of Mechanics B/Fluids, vol. 40, pp. 87-106, 2013.

[3] Broukal, J., Hajek, J., "Validation of an effervescent spray model with secondary atomization and its application to modeling of a large - scale furnace," Applied Thermal Engineering, vol. 31, pp. 2153-2164, 2011.

[4] Qi, D.H., Chen, H., Matthews, R.D., Bian, Y. ZH., "Combustion and emission characteristics of ethanol-biodiesel-water micro-emulsions used in a direct injection compression ignition engine," Fuel, vol. 89, pp. 958-964, 2010.

[5] Lif, A., Holmberg, K., "Water-in-diesel emulsions and related systems," Advances in Colloid and Interface Science, vol. 132-126, pp. 231-239, 2006.

[6] J.A. García, A. Lozano, J. Alconchel, E. Calvo, F. Barreras, J.L. Santolaya, "Atomization of glycerin with a twin-fluid swirl nozzle," International Journal of Multiphase Flow, vol. 92, pp. 150-160, 2017.

[7] Mlkvik, M. , Stähle, P. , Schuchmann, H.P. , Gaukel, V. , Jedelsky, J. , Jicha, M., "Twin-fluid atomization of viscous liquids: the effect of atomizer construction on breakup process, spray stability and droplet size," International Journal of Multiphase Flow, vol. 77, pp.19-31. 2015.

[8] Glassman, I., Yetter, R. A., "Combustion," Academic Press. Elsevier Inc. United States of America. Fourth Edition. 2007. (references)

[9] Charalampous, G., Hadjiyiannis, C., Hardalupas, Y., "Comparative measurement of the breakup length of liquid jets in airblast atomisers using optical connectivity, electrical connectivity and shadowgraphy," Measurement, vol. 89, pp. 288-299, 2016. 